Provided for non-commercial research and education use. Not for reproduction, distribution or commercial use.

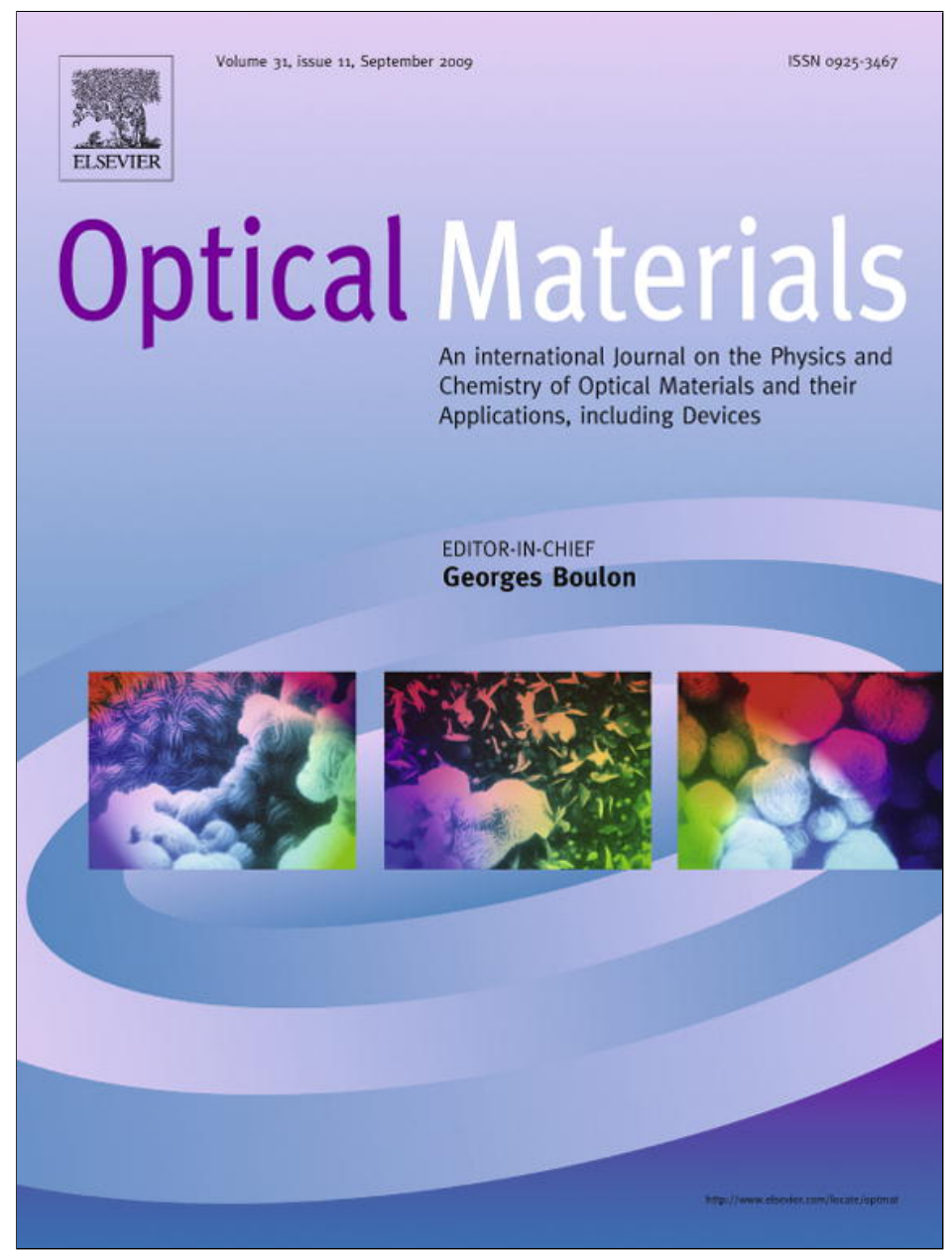

This article appeared in a journal published by Elsevier. The attached copy is furnished to the author for internal non-commercial research and education use, including for instruction at the authors institution and sharing with colleagues.

Other uses, including reproduction and distribution, or selling or licensing copies, or posting to personal, institutional or third party websites are prohibited.

In most cases authors are permitted to post their version of the article (e.g. in Word or Tex form) to their personal website or institutional repository. Authors requiring further information regarding Elsevier's archiving and manuscript policies are encouraged to visit:

http://www.elsevier.com/copyright 


\title{
Emission spectra of lanthanide ions in hexafluoroelpasolite lattices excited by synchrotron radiation
}

\author{
Peter A. Tanner ${ }^{\mathrm{a}, *}$, Chang-Kui Duan ${ }^{\mathrm{a}, 1}$, Vladimir N. Makhov ${ }^{\mathrm{b}}$, Marco Kirm ${ }^{\mathrm{c}}$, Nicholas M. Khaidukov ${ }^{\mathrm{d}}$ \\ ${ }^{a}$ Department of Biology and Chemistry, City University of Hong Kong, Tat Chee Avenue, Kowloon, Hong Kong S.A.R., People's Republic of China \\ b P.N. Lebedev Physical Institute, Leninskii Prospect 53, 119991 Moscow, Russia \\ ${ }^{\mathrm{c}}$ Institute of Physics, University of Tartu, Riia 142, 51014 Tartu, Estonia \\ ${ }^{\mathrm{d}}$ Kurnakov Institute of General and Inorganic Chemistry, Leninskii Prospect 31, 119991 Moscow, Russia
}

\section{A R T I C L E I N F O}

\section{Article history:}

Received 18 February 2009

Received in revised form 5 May 2009

Accepted 6 May 2009

Available online 6 June 2009

\section{PACS:}

78.55.Hx

71.70. $-\mathrm{d}$

78.47.+p

78.60.Ya

\section{Keywords:}

Synchrotron radiation

Luminescence

Lanthanide ion

Elpasolite crystals

VUV

\begin{abstract}
A B S T R A C T
Emission spectra at $10 \mathrm{~K}$ employing synchrotron radiation have been recorded for the tripositive lanthanide ions, $\mathrm{Ln}=\mathrm{Sm}, \mathrm{Gd}, \mathrm{Tb}, \mathrm{Ho}$, and Er situated at octahedral (or nearly octahedral) site symmetry in hexafluoroelpasolite $\mathrm{Cs}_{2} \mathrm{NaMF}_{6}(\mathrm{M}=\mathrm{Y}$, Sc, or $\mathrm{Ga}$ ) lattices. Interconfigurational $5 \mathrm{~d} \rightarrow 4 \mathrm{f}$ transitions are only observed for $\mathrm{Er}^{3+}$, and the intensity ratio of $4 \mathrm{f}^{10} 5 \mathrm{~d} \rightarrow 4 \mathrm{f}^{11}$ emission, compared with $4 \mathrm{f}^{11} \rightarrow 4 \mathrm{f}^{11}$ emission, with excitation into $5 \mathrm{~d}$ levels, is greater for $\mathrm{M}=\mathrm{Ga}$ than $\mathrm{M}=\mathrm{Sc}$. The highest energy intraconfigurational emission is from ${ }^{4} \mathrm{G}_{5 / 2}\left(\mathrm{Sm}^{3+}\right),{ }^{6} \mathrm{P}_{7 / 2}\left(\mathrm{Gd}^{3+}\right),{ }^{5} \mathrm{D}_{3}\left(\mathrm{~Tb}^{3+}\right),{ }^{5} \mathrm{G}_{4}\left(\mathrm{Ho}^{3+}\right)$, and ${ }^{2} \mathrm{~F}(2)_{7 / 2}\left(\mathrm{Er}^{3+}\right)$. Detailed energy level assignments have been given for $\mathrm{Ln}=\mathrm{Sm}, \mathrm{Gd}$, and the remaining spectra are assigned as multiplet-multiplet transitions.
\end{abstract}

(c) 2009 Elsevier B.V. All rights reserved.

\section{Introduction}

The luminescence of lanthanide ions $\left(\mathrm{Ln}^{3+}\right)$ doped into fluoride hosts has attracted much attention in recent years due to the possible applications in mercury free fluorescent tubes, plasma display panels, vacuum ultraviolet (VUV) scintillators, or tunable ultraviolet (UV) solid-state laser materials. Fluoride crystal hosts possess greater thermal stability and relative inertness compared to other halide hosts, and lower synthesis temperatures and higher band gap energies compared to oxide hosts. The most popular fluoride crystal hosts that have been extensively investigated are $\mathrm{MYF}_{4}$ $(\mathrm{M}=\mathrm{Li}, \mathrm{Na})$ and $\mathrm{MF}_{2}(\mathrm{M}=\mathrm{Ca}, \mathrm{Sr})$. In the former $(\mathrm{M}=\mathrm{Li})$, the $\mathrm{Ln}^{3+}$ ions are situated at $S_{4}$ site symmetry, whereas in the alkali metal fluorides there are several available sites due to charge incompatibility. The hexafluoroelpasolite hosts offer the advantage of a unique site for $\mathrm{Ln}^{3+}$ with octahedral symmetry. This leads to higher

\footnotetext{
* Corresponding author. Fax: +852 27887406.

E-mail address: bhtan@cityu.edu.hk (P.A. Tanner).

1 Present address: Institute of Modern Physics, Chongqing University of Post and Telecommunications, Chongqing 400065, PR China.
}

degeneracies of energy levels and stricter transition selection rules. The theoretical consequences of these are that fewer crystal field parameters are required to model the $4 \mathrm{f}^{\mathrm{N}}$ and $4 \mathrm{f}^{\mathrm{N}-1} 5 \mathrm{~d}$ energy levels of $\mathrm{Ln}^{3+}$ in these elpasolite hosts: one parameter for $5 \mathrm{~d}$ and two parameters for $4 \mathrm{f}^{\mathrm{N}}$. The spectral consequences are that whilst the $4 \mathrm{f}^{\mathrm{N}} \rightarrow 4 \mathrm{f}^{\mathrm{N}-1} 5 \mathrm{~d}$ transitions are electric dipole allowed, the pure electronic $4 \mathrm{f}^{\mathrm{N}} \rightarrow 4 \mathrm{f}^{\mathrm{N}}$ transitions are forbidden by that mechanism, but some are magnetic dipole allowed. The sidebands of the intraconfigurational electronic transitions consist of single quanta of odd-parity vibrational modes [1].

Recently, we have investigated the VUV excitation spectra of several $\mathrm{Ln}^{3+}$ doped into hexafluoroelpasolite lattices [2]. In the present study, the emission spectra of the tripositive ions of $\mathrm{Sm}$, $\mathrm{Gd}, \mathrm{Tb}, \mathrm{Ho}$, and Er excited by synchrotron radiation at $\sim 10 \mathrm{~K}$ are presented and detailed interpretations are provided where possible. There have been some previous $4 \mathrm{f}^{\mathrm{N}}-4 \mathrm{f}^{\mathrm{N}}$ emission results reported for hexafluoroelpasolite systems comprising $\mathrm{Nd}^{3+}$ [3], $\mathrm{Eu}^{3+}$ $[4], \mathrm{Tb}^{3+}[5,6], \mathrm{Er}^{3+}[7], \mathrm{Tm}^{3+}[8]$, and $\mathrm{Yb}^{3+}[9]$, and experimental results and/or theoretical simulations of $4 \mathrm{f}^{\mathrm{N}} \leftrightarrow 4 \mathrm{f}^{\mathrm{N}-1} 5 \mathrm{~d}$ spectra were reported for $\mathrm{Ce}^{3+}[10,11], \mathrm{Pr}^{3+}[12], \mathrm{Nd}^{3+}[3], \mathrm{Er}^{3+}[13]$, and $\mathrm{Tm}^{3+}$ $[13,14]$. 


\section{Experimental section}

The $\mathrm{Cs}_{2} \mathrm{NaYF}_{6}$ single crystals doped with $\mathrm{Sm}^{3+}$ (nominal concentration 3.0 atom \% - hereafter abbreviated to $3.0 \%), \mathrm{Gd}^{3+}(6.0 \%$, $30.0 \%$, and $50.0 \%), \mathrm{Tb}^{3+}(1.0 \%)$, and $\mathrm{Ho}^{3+}(10.0 \%)$ as well as $\mathrm{Cs}_{2} \mathrm{NaM}-$ $\mathrm{F}_{6}: \mathrm{Er}^{3+}(\mathrm{M}=\mathrm{Ga}$, Sc; $50 \%)$ were synthesized under hydrothermal conditions [4]. The crystallographic details for the host lattices are available [15-17]. All compounds have a cubic elpasolite-type structure and crystallize in the space group $F m 3 m$, except for $\mathrm{Cs}_{2} \mathrm{NaGaF}_{6}$ which has the rhombohedral 12L-type crystal structure and belongs to the space group $R-3 m$. The (VI) ionic radii of $\mathrm{Ga}^{3+}$ $(620 \mathrm{pm})$ and $\mathrm{Er}^{3+}(890 \mathrm{pm})$ differ considerably, whereas the radii

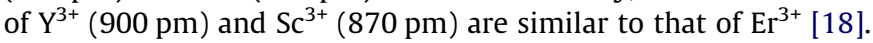

The measurements were performed at the SUPERLUMI station [19] of HASYLAB at DESY, using synchrotron radiation from the DORIS storage ring for excitation in the spectral range 70$280 \mathrm{~nm}$. Emission spectra in the spectral range 200-1000 nm were recorded using a $0.3 \mathrm{~m}$ Czerny-Turner monochromator-spectrograph SpectraPro-308i (Acton Research Inc.) with a liquid nitrogen cooled CCD detector (Princeton Instruments Inc.). The spectral resolution of $\sim 0.5 \mathrm{~nm}$ was achieved with the 300 grooves $/ \mathrm{mm}$ grating using $0.05 \mathrm{~mm}$ slit width. Emission spectra in the spectral range around $300 \mathrm{~nm}$ were measured (for $\mathrm{Gd}^{3+}$ doped samples) with higher spectral resolution $(\sim 0.2 \mathrm{~nm})$ using the 1200 grooves $/ \mathrm{mm}$ grating. Emission spectra were not corrected for the spectral response of the detection system. The possible presence of emission in VUV spectral range (for $\mathrm{Gd}^{3+}$ doped crystals) was checked using a Pouey type monochromator equipped with a CsI sensitized microsphere plate detector.

The crystals were cleaved prior to mounting onto the sample holder in a flow-type liquid helium cryostat. The crystallographic axes of the crystals when installed onto the sample holder were not oriented with respect to the polarization vector of exciting radiation. All measurements have been performed under ultrahigh-vacuum conditions.

\section{Results and discussion}

The following results present the VUV-excited emission spectra of the ions $\mathrm{Sm}^{3+}, \mathrm{Gd}^{3+}, \mathrm{Tb}^{3+}, \mathrm{Ho}^{3+}$, and $\mathrm{Er}^{3+}$ in hexafluoroelpasolite lattices, as now described one by one.

\section{1. $\mathrm{Sm}^{3+}$}

Due to the overlap of the extensive $4 \mathrm{f}^{5}$ configuration with $4 \mathrm{f}^{4} 5 \mathrm{~d}$, no emission has thus far been observed from $5 d$ levels of $\mathrm{Sm}^{3+}$ under VUV excitation [20]. Optical emission spectra have been reported for $\mathrm{Cs}_{2} \mathrm{NaYCl}_{6}: \mathrm{Sm}^{3+}[21,22], \quad \mathrm{LiYF}_{4}: \mathrm{Sm}^{3+}[23]$, and $\mathrm{Sr}_{5}\left(\mathrm{PO}_{4}\right)_{3} \mathrm{~F}: \mathrm{Sm}^{3+}[24]$ and in each case the highest luminescence state was $4 \mathrm{f}^{5}{ }^{4} \mathrm{G}_{5 / 2}$, near $18,000 \mathrm{~cm}^{-1}$, since there is an energy gap of $\sim 7100 \mathrm{~cm}^{-1}$ below this multiplet term [25]. Fig. 1 shows the $12.3 \mathrm{~K}$ emission spectrum of $\mathrm{Cs}_{2} \mathrm{NaYF}_{6}: \mathrm{Sm}^{3+}$ under VUV excitation at $169.7 \mathrm{~nm}$. The three groups of bands in Fig. 1a correspond to transitions from the mixed $\left({ }^{4} \mathrm{G}+{ }^{4} \mathrm{~F}\right)_{5 / 2} \Gamma_{8}$ level (hereafter, written as ${ }^{4} \mathrm{G}_{5 / 2} \Gamma_{8}$, where the $O$ double group notation is employed, and the subscript u for all $4 \mathrm{f}^{5}$ levels has been omitted) at $17,790 \mathrm{~cm}^{-1}$ to ${ }^{6} \mathrm{H}_{J}(2 J=5,7,9)$ multiplets. The next-highest level above ${ }^{4} \mathrm{G}_{5 / 2} \Gamma_{8}$ does not contribute hot bands to the spectrum at $10 \mathrm{~K}$ since even in $\mathrm{Cs}_{2} \mathrm{NaSmCl}_{6}$ it is $344 \mathrm{~cm}^{-1}$ higher. The most intense bands correspond to magnetic dipole transitions, which are allowed to all terminal $\Gamma_{i}(i=6,7,8)$ levels and serve to confirm the symmetry of the luminescent level, since transitions are not entirely allowed for initial $\Gamma_{6}$ and $\Gamma_{7}$ levels. The terminal electronic levels are marked in the figure. The derived vibrational wavenumbers for vibronic structure are $\left(\right.$ in $\left.\mathrm{cm}^{-1}\right): \mathrm{S}_{5} 64 ; v_{4}\left(\mathrm{~S}_{7}\right) 154,177 ; v_{6}\left(\mathrm{~S}_{10}\right)$
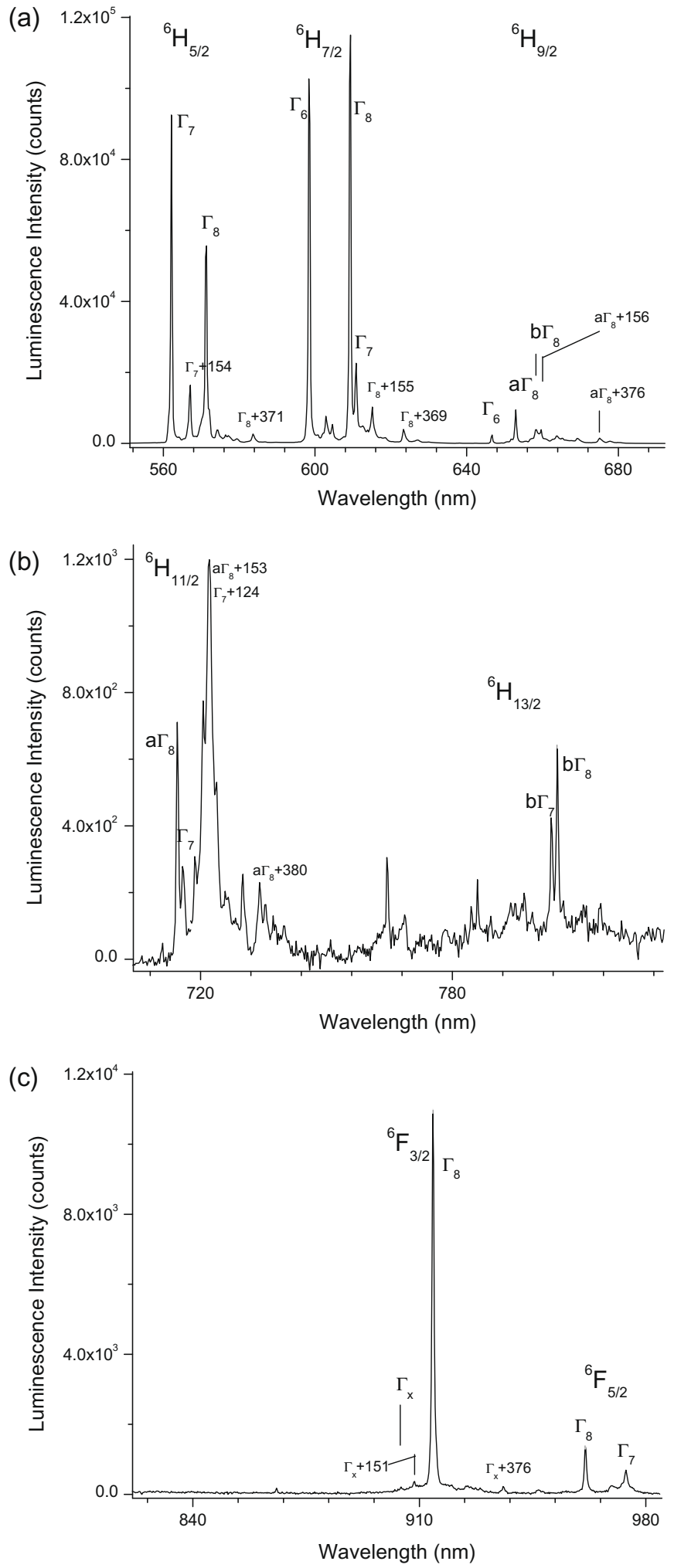

Fig. 1. $12.3 \mathrm{~K}$ emission spectrum of $\mathrm{Cs}_{2} \mathrm{NaYF}_{6}: \mathrm{Sm}^{3+}$ under VUV excitation at $169.7 \mathrm{~nm}$ between: (a) $550 \mathrm{~nm}$ and $690 \mathrm{~nm}$; (b) $703 \mathrm{~nm}$ and $830 \mathrm{~nm}$; (c) $895 \mathrm{~nm}$ and $975 \mathrm{~nm}$. The luminescent level is ${ }^{4} G_{5 / 2} \Gamma_{8}$. Terminal multiplet terms and levels are marked, together with some of the prominent vibronic bands.

123; $\mathrm{S}_{8} 250$; and $v_{3}\left(\mathrm{~S}_{6}\right) 373,437$, where the notations refer to moiety and unit cell group modes, respectively. Much weaker structure is observed in Fig. $2 \mathrm{~b}$, corresponding to transitions to terminal ${ }^{6} \mathrm{H}_{11 / 2}$ and ${ }^{6} \mathrm{H}_{13 / 2}$ multiplet terms. The assignments for these bands and for the ones to lower energy require further substantiation 

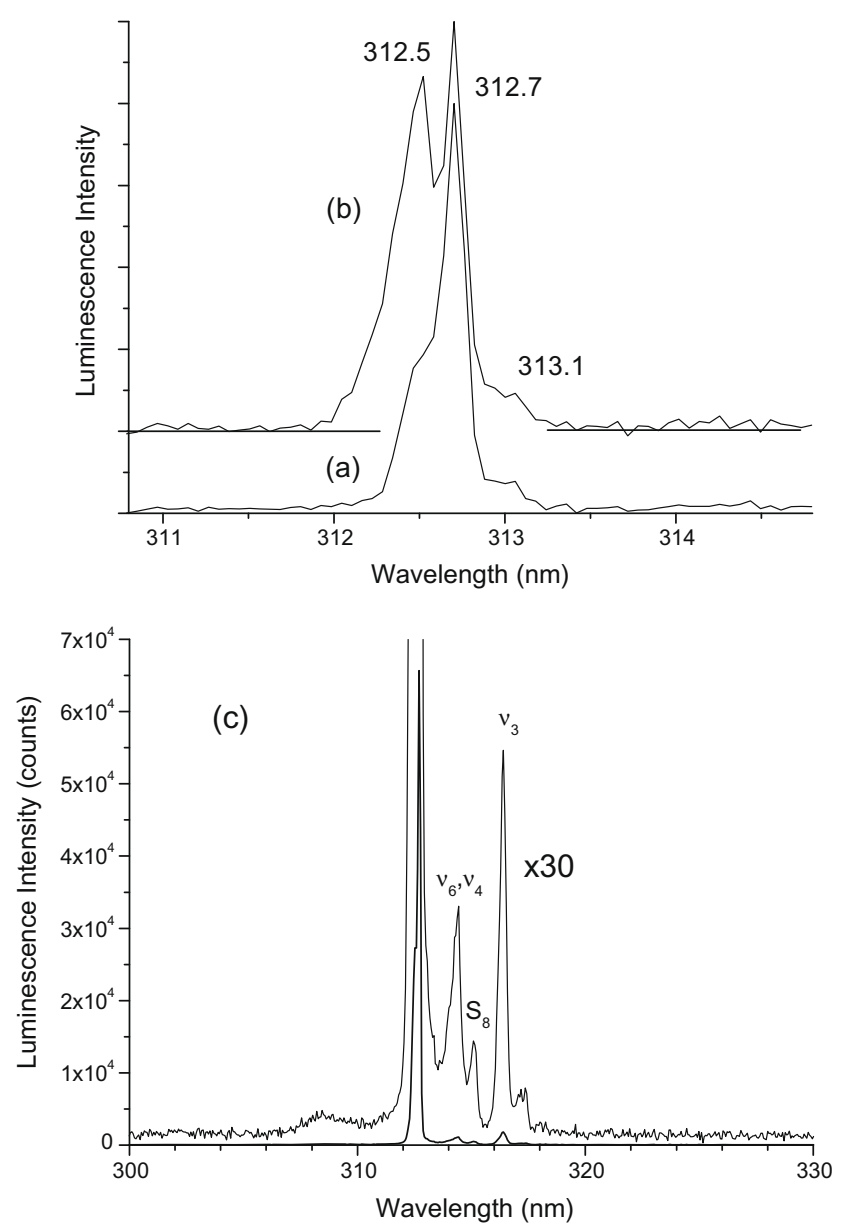

Fig. 2. (a and b) $125.1 \mathrm{~nm}$ excited emission spectrum between $310.8 \mathrm{~nm}$ and $314.9 \mathrm{~nm}$ of $\mathrm{Cs}_{2} \mathrm{NaYF}_{6}: \mathrm{Gd}^{3+}(6 \%)$ at $8 \mathrm{~K}$ (a) and $28.7 \mathrm{~K}$ (b). The peak positions are marked. (c) $131.4 \mathrm{~nm}$ excited $8.5 \mathrm{~K}$ emission spectrum of $\mathrm{Cs}_{2} \mathrm{NaYF}_{6}: \mathrm{Gd}^{3+}(50 \%)$ between $300 \mathrm{~nm}$ and $330 \mathrm{~nm}$. The vibronic origins are indicated.

from absorption measurements and luminescence spectra under higher sensitivity. There is guide to the band assignments for ${ }^{4} \mathrm{G}_{5 / 2} \rightarrow{ }^{6} \mathrm{H}_{11 / 2}$ from the analogous transition in $\mathrm{Cs}_{2} \mathrm{NaYCl}_{6}: \mathrm{Sm}^{3+}$ [21], where the first two prominent bands were assigned to $\Gamma_{8} \rightarrow \mathrm{a} \Gamma_{8}$ and $\Gamma_{8} \rightarrow \mathrm{a} \Gamma_{8}+v_{6}$. Similar assignments are indicated in Fig. $1 \mathrm{~b}$ but are tentative, as are those for the very weak transitions to ${ }^{6} \mathrm{H}_{13 / 2}$. The next group of bands between $895 \mathrm{~nm}$ and $975 \mathrm{~nm}$ is shown in Fig. 1c. The assignment of the strongest band is made to ${ }^{6} \mathrm{~F}_{3 / 2}$ rather than to ${ }^{6} \mathrm{H}_{15 / 2}$ from the magnetic dipole selection rules for $\Delta J$. The two weaker bands in Fig. 1c are similarly associated with transitions to ${ }^{6} \mathrm{~F}_{5 / 2}$ terminal states. However, a very weak unassigned transition (from $\Gamma_{x}$ ) is also indicated. The energy level assignments for $\mathrm{Sm}^{3+}$ in $\mathrm{Cs}_{2} \mathrm{NaYF}_{6}$ are collected in Table 1 and compared with those for the analogous chloride [25].

For electric dipole allowed transitions, the emission from ${ }^{4} \mathrm{G}_{5 / 2}$ is allowed by the rank-2 effective transition operator characterized by parameter $\Omega_{2}$ to multiplets ${ }^{6} \mathrm{H}_{J}(2 J=5,7,9)$ by the angular-momentum selection rule, and rank- 4 and rank- 6 operators to more multiplets. This is shown by the cases of $\mathrm{LiYF}_{4}: \mathrm{Sm}^{3+}$ [23] and $\mathrm{Sr}_{5}\left(\mathrm{PO}_{4}\right)_{3} \mathrm{~F}: \mathrm{Sm}^{3+}$ [24], where the greatest intensity arises from $\Omega_{2}$ in the electric dipole pure electronic transitions to ${ }^{6} \mathrm{H}_{9 / 2}$. In the present case, most intensity comes from magnetic dipole transitions so that $\Delta J=0,1$.

\section{2. $G d^{3+}$}

The $4 \mathrm{f}^{7}$ electronic ground state of $\mathrm{Gd}^{3+}{ }^{3}{ }^{8} \mathrm{~S}_{7 / 2}\left(\Gamma_{6}+\Gamma_{7}+\Gamma_{8}\right)$, with the transition to the first excited $4 \mathrm{f}^{7}$ state, ${ }^{6} \mathrm{P}_{7 / 2}$, being in the region of 310-315 nm [26-28]. In $\mathrm{Cs}_{2} \mathrm{NaGdCl}_{6}$, the ${ }^{6} \mathrm{P}_{7 / 2}$ crystal field levels are located at $\left(\right.$ in $\left.\mathrm{cm}^{-1}\right): 31951\left(\Gamma_{7}\right), 31968\left(\Gamma_{8}\right)$, and $31980\left(\Gamma_{6}\right)$ and the $4 \mathrm{f}^{7} \rightarrow 4 \mathrm{f}^{7}$ emission spectrum has been reported by de Vries and Blasse [26]. Upconverted emission has been reported from ${ }^{6} \mathrm{G}_{J}$ in $\mathrm{Cs}_{2} \mathrm{NaGdCl}_{6}$ at room temperature, but the assignments are not consistent [29].

As was recently found [30,31], some wide band-gap fluoride crystals doped with $\mathrm{Gd}^{3+}$ show fast VUV luminescence due to $5 \mathrm{~d}-4 \mathrm{f}$ transitions of $\mathrm{Gd}^{3+}$. However, no VUV luminescence has been detected from our $\mathrm{Gd}^{3+}$ doped elpasolite crystals. Luminescence from the high-lying ${ }^{6} \mathrm{G}_{7 / 2}$ level of $\mathrm{Gd}^{3+}$, in particular, orange (590-640 nm) luminescence due to $4 \mathrm{f}^{7}{ }^{6} \mathrm{G}_{7 / 2}{ }^{-6} \mathrm{P}_{J}(2 J=7,5,3)$ transitions, was also not detected under $\mathrm{Gd}^{3+} 4 \mathrm{f}^{7}-4 \mathrm{f}^{6} 5 \mathrm{~d}$ excitation. The reason for these effects can be that the band-gap energy of the $\mathrm{Cs}_{2} \mathrm{NaYF}_{6}$ crystal is not high enough for the existence of radiative decay from the lowest level of the $\mathrm{Gd}^{3+} 4 \mathrm{f}^{6} 5 \mathrm{~d}$ electronic configuration. The onset of the $4 \mathrm{f}^{6} 5 \mathrm{~d}$ levels is at $\sim 132 \mathrm{~nm}\left(\sim 75,760 \mathrm{~cm}^{-1}\right)$. The energy of the $4 f^{6} 5 \mathrm{~d}$ excitation is transferred nonradiatively to host-related excitations resulting, after some kind of relaxation, in the appearance of $4 \mathrm{f}-4 \mathrm{f}$ luminescence from lower-lying $\mathrm{Gd}^{3+} 4 \mathrm{f}$ levels $\left({ }^{6} \mathrm{P}_{7 / 2}\right.$ ). Luminescence from the ${ }^{6} \mathrm{G}_{7 / 2}$ level of $\mathrm{Gd}^{3+}$ was also not detected under direct ${ }^{6} \mathrm{G}_{7 / 2}$ level excitation (around $200 \mathrm{~nm}$ ).

The highest energy band in the $8 \mathrm{~K}$ emission spectrum of $\mathrm{Cs}_{2} \mathrm{NaYF}_{6}: \mathrm{Gd}^{3+}(6 \%)$ under $125.1 \mathrm{~nm}$ excitation is shown in Fig. 2a. On warming to $28.7 \mathrm{~K}$, Fig. $2 \mathrm{~b}$, the shoulder at $312.5 \mathrm{~nm}$ gains intensity and is comparably as strong as the main band at $312.7 \mathrm{~nm}$. The lowest energy band is therefore assigned to a phonon, whereas the two features at $312.7,312.5 \mathrm{~nm}$ (separated by $20 \mathrm{~cm}^{-1}$ ) are assigned to the lowest luminescent levels of ${ }^{6} \mathrm{P}_{7 / 2}$ : $\Gamma_{7}$ at $31980 \mathrm{~cm}^{-1}$ and $\Gamma_{8}$ at $31200 \mathrm{~cm}^{-1}$. Fig. 2c shows the $8.5 \mathrm{~K}$

Table 1

Comparison of $4 \mathrm{f}^{5}$ energy levels in $\mathrm{Cs}_{2} \mathrm{NaSmCl}_{6}$ and $\mathrm{Cs}_{2} \mathrm{NaYF}_{6}: \mathrm{Sm}^{3+}$

\begin{tabular}{|c|c|c|c|c|}
\hline \multirow{2}{*}{$\begin{array}{l}\text { Multiplet } \\
\text { term }\end{array}$} & \multirow{2}{*}{$\begin{array}{l}\mathrm{CF}^{\mathrm{a}} \\
\text { irrep }^{\mathrm{b}}\end{array}$} & \multicolumn{2}{|c|}{ Energy $\left(\mathrm{cm}^{-1}\right) \mathrm{Cs}_{2} \mathrm{NaYF}_{6}: \mathrm{Sm}^{3+}$} & \multirow{2}{*}{$\begin{array}{l}\text { Energy }\left(\mathrm{cm}^{-1}\right) \\
\mathrm{Cs}_{2} \mathrm{NaSmCl}_{6}{ }^{\mathrm{c}} \\
\mathrm{CF}^{\mathrm{a}} \text { level }^{\mathrm{d}}\end{array}$} \\
\hline & & $\begin{array}{l}\text { Transition from }{ }^{4} G_{5 /} \\
{ }_{2} \Gamma_{8}\end{array}$ & $\begin{array}{l}\mathrm{CF}^{\mathrm{a}} \\
\text { level }\end{array}$ & \\
\hline${ }^{6} \mathrm{H}_{5 / 2}$ & $\Gamma_{7}$ & 17,790 & 0 & 0 \\
\hline${ }^{6} \mathrm{H}_{5 / 2}$ & $\Gamma_{8}$ & 17,504 & 286 & 165 \\
\hline${ }^{6} \mathrm{H}_{7 / 2}$ & $\Gamma_{6}$ & 16,711 & 1079 & 1044 \\
\hline${ }^{6} \mathrm{H}_{7 / 2}$ & $\Gamma_{8}^{\mathrm{e}}$ & 16,413 & 1377 & 1208 \\
\hline${ }^{6} \mathrm{H}_{7 / 2}$ & $\Gamma_{7}^{\mathrm{e}}$ & 16,371 & 1419 & 1216 \\
\hline${ }^{6} \mathrm{H}_{9 / 2}$ & $\Gamma_{6}$ & 15,464 & 2326 & 2251 \\
\hline${ }^{6} \mathrm{H}_{9 / 2}$ & $\mathrm{a}_{8}$ & 15,316 & 2474 & 2369 \\
\hline${ }^{6} \mathrm{H}_{9 / 2}$ & $\mathrm{~b}_{8}$ & 15,191 & 2599 & 2423 \\
\hline${ }^{6} \mathrm{H}_{11 / 2}$ & $a \Gamma_{8}$ & 13,997 & 3790 & 3641 \\
\hline${ }^{6} \mathrm{H}_{11 / 2}$ & $\Gamma_{7}^{\circ}$ & 13,970 & 3820 & [3676] \\
\hline${ }^{6} \mathrm{H}_{11 / 2}$ & $\mathrm{~b} \Gamma_{8}$ & - & - & 3692 \\
\hline${ }^{6} \mathrm{H}_{11 / 2}$ & $\Gamma_{6}$ & $(13,888)$ & $(3902)$ & 3705 \\
\hline${ }^{6} \mathrm{H}_{13 / 2}$ & $a \Gamma_{8}$ & - & - & 5005 \\
\hline${ }^{6} \mathrm{H}_{13 / 2}$ & $\Gamma_{6}$ & - & - & (5012) \\
\hline${ }^{6} \mathrm{H}_{13 / 2}$ & $a \Gamma_{7}$ & - & - & 5027 \\
\hline${ }^{6} \mathrm{H}_{13 / 2}$ & $\mathrm{~b} \Gamma_{7}$ & $(12,444)$ & (5346) & 5139 \\
\hline${ }^{6} \mathrm{H}_{13 / 2}$ & $\mathrm{~b}_{8}$ & $(12,422)$ & (5368) & 5146 \\
\hline${ }^{6} \mathrm{H}_{15 / 2}$ & $a \Gamma_{8}$ & $(11,547)$ & (6243) & (6285) \\
\hline${ }^{6} \mathrm{~F}_{1 / 2}$ & $\Gamma_{6}$ & - & - & 6355 \\
\hline${ }^{6} \mathrm{H}_{15 / 2}$ & $\mathrm{~b} \Gamma_{8}$ & - & - & (6397) \\
\hline${ }^{6} \mathrm{~F}_{3 / 2}$ & $\Gamma_{8}{ }^{\circ}$ & 10,939 & 6851 & 6611 \\
\hline${ }^{6} \mathrm{H}_{15 / 2}$ & $\Gamma_{7}$ & - & - & [6630] \\
\hline${ }^{6} \mathrm{H}_{15 / 2}$ & $\mathrm{Cl}_{8}$ & - & - & (6759) \\
\hline${ }^{6} \mathrm{H}_{15 / 2}$ & $\Gamma_{6}$ & - & - & [6795] \\
\hline${ }^{6} \mathrm{~F}_{5 / 2}$ & $\Gamma_{8}$ & 10,403 & 7387 & 7106 \\
\hline${ }^{6} \mathrm{~F}_{5 / 2}$ & $\Gamma_{7}$ & 10,268 & 7522 & 7181 \\
\hline${ }^{4} G_{5 / 2}$ & $\Gamma_{8}$ & - & 17,790 & 17,742 \\
\hline
\end{tabular}

a Crystal field.

b Irreducible representation.

c From [25].

d Calculated values are in square brackets. Uncertain experimental values are in parentheses.

e There is a mis-print in Table 2 of [22]. 
spectrum of $\mathrm{Cs}_{2} \mathrm{NaYF}_{6}: \mathrm{Gd}^{3+}$ (50\%), which has a better signal-tonoise ratio. The vibronic structure to lower energy of the zero phonon lines corresponds to the odd-parity $v_{i}(i=3,4,6)$ and $\mathrm{S}_{8}$ vibrations. The first member of the $v_{1}$ progression on the electronic origin is observed at $471 \mathrm{~cm}^{-1}$.

\section{3. $T b^{3+}$}

The $219.5 \mathrm{~nm}$ excited emission spectrum of $\mathrm{Cs}_{2} \mathrm{NaYF}_{6}: \mathrm{Tb}^{3+}$ between $370 \mathrm{~nm}$ and $720 \mathrm{~nm}$ is shown in Fig. 3a and b. The intraconfigurational $355 \mathrm{~nm}$ excited luminescence of $\mathrm{Cs}_{2} \mathrm{NaTbF}_{6}$ at $10 \mathrm{~K}$ and $77 \mathrm{~K}$ at higher resolution than in Fig. 3 has previously been reported by Berry et al. $[5,6]$ and the assignment of magnetic dipole transitions enabled the elucidation of the $4 \mathrm{f}^{8}$ energy level scheme. The assignments were based upon the observation of sharp features, rather than the broader vibronic sidebands. Although there could be problems with this approach if sharp bands are present due to luminescence from defect sites, such features were mostly absent. Our assignments of the vibronic structure in Ref. [5] for the region from $376-658 \mathrm{~nm}\left(26,600-15,200 \mathrm{~cm}^{-1}\right)$ serve to substantiate the energy level scheme presented therein. The vibrations that appear in the sidebands are $\left(\right.$ in $\left.\mathrm{cm}^{-1}\right): v_{6}\left(\mathrm{~S}_{10}\right) 121,134 ; v_{4}\left(\mathrm{~S}_{7}\right)$ 156,$176 ; v_{3}\left(\mathrm{~S}_{6}\right) 366,381,452 ; \mathrm{S}_{8} 249$. Berry et al. [6] have discussed the previous report of the $100 \mathrm{~K}$ emission spectrum of $\mathrm{Cs}_{2} \mathrm{KYF}_{6}: \mathrm{Tb}^{3+}$ by Amberger [32].
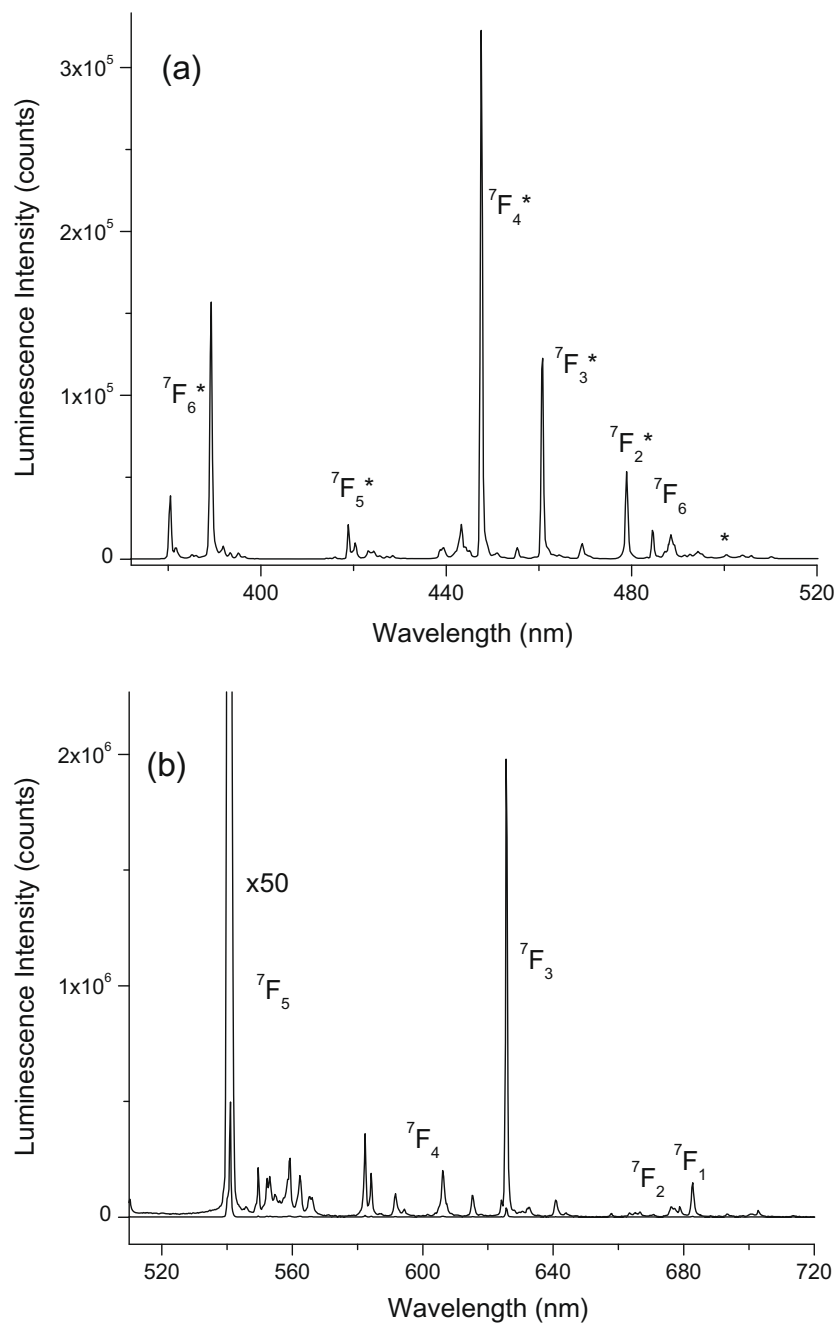

Fig. 3. $219.5 \mathrm{~nm}$ excited emission spectrum at $12.3 \mathrm{~K}$ of $\mathrm{Cs}_{2} \mathrm{NaYF}_{6}: \mathrm{Tb}^{3+}$ between $200 \mathrm{~nm}$ and $740 \mathrm{~nm}$. Some of the terminal electronic states are marked and are starred for emission from ${ }^{5} \mathrm{D}_{3}$, but unstarred for ${ }^{5} \mathrm{D}_{2}$.
The onset of the $4 f^{8} \rightarrow 4 f^{7} 5 d$ absorption bands in $\mathrm{Cs}_{2} \mathrm{NaYF}_{6}: \mathrm{Tb}^{3+}$ is at $\sim 265 \mathrm{~nm}$ [2]. Excitation into the spin-allowed transition at $219.5 \mathrm{~nm}$ (Fig. 3) does not lead to $5 \mathrm{~d}-4 \mathrm{f}$ emission because the $4 \mathrm{f}^{7} 5 \mathrm{~d}$ levels are depopulated to the ladder of overlapping $4 \mathrm{f}^{8}$ energy levels. The highest energy luminescence at $\sim 380 \mathrm{~nm}$ corresponds to intraconfigurational transitions originating from ${ }^{5} \mathrm{D}_{3} \Gamma_{2}$ at $36383 \mathrm{~cm}^{-1}$. In Fig. 3, the terminal multiplet terms are labeled, and the comparison with the spectrum of Berry et al. [5,6] shows some differences, besides the absence of some hot bands herein. First, the emission from ${ }^{5} \mathrm{D}_{3}$ is relatively more intense, with respect to that from ${ }^{5} \mathrm{D}_{2}$, in the present case. Therefore the transitions to shorter wavelengths than $400 \mathrm{~nm}$ appear more prominent herein. The starred band at $\sim 500 \mathrm{~nm}$ in Fig. $3 \mathrm{a}$ is absent in the spectrum of [5] and corresponds to the ${ }^{5} \mathrm{D}_{3} \Gamma_{2} \rightarrow{ }^{7} \mathrm{~F}_{1} \Gamma_{4}+v_{3}$ transition. Second, some broad bands in $[5,6]$ are absent herein. These features are located between $18,380-18,200 \mathrm{~cm}^{-1}(544-549 \mathrm{~nm})$ in $[5,6]$ and correspond to emission from another species. Indeed, in this region the assignment of the ${ }^{5} \mathrm{D}_{2} \rightarrow{ }^{7} \mathrm{~F}_{5}$ transition was problematic (but correct) in [6]. The separation of the two $\Gamma_{4}$ states of ${ }^{5} D_{5}$ at $10 \mathrm{~K}$ is $477 \mathrm{~cm}^{-1}$. This energy is very similar to that expected for the $v_{1}$ vibrational quantum, which is $468 \mathrm{~cm}^{-1}$ at room temperature [5], but the presence of a vibrational progression in $v_{1}$ for the higher energy transition from ${ }^{5} \mathrm{D}_{3}$ to ${ }^{7} \mathrm{~F}_{5}$ can be ruled out. Finally, the assignment of the ${ }^{7} \mathrm{~F}_{0} \Gamma_{1}$ level is unclear.

\section{4. $\mathrm{Ho}^{3+}$}

Fig. 4 shows the emission spectrum of $\mathrm{Cs}_{2} \mathrm{NaYF}_{6}: \mathrm{Ho}^{3+}$ (10 at.\%) under the excitation at $119.2 \mathrm{~nm}$ by synchrotron radiation. The major bands are assigned to the emission from the ${ }^{5} \mathrm{~S}_{2}$ multiplet term to ${ }^{5} \mathrm{I}_{8}$ and ${ }^{5} \mathrm{I}_{7}$ levels. The assignment is based on the corresponding emission spectra of $\mathrm{Cs}_{2} \mathrm{NaHoCl}_{6}$ [33], where the ${ }^{5} \mathrm{~S}_{2}$ $\Gamma_{5}, \Gamma_{3}$ levels are located at $18,387,18,365 \mathrm{~cm}^{-1}$, respectively. The separation of ca. $5120 \mathrm{~cm}^{-1}$ between the first bands in the two groups agrees with the separation between ${ }^{5} \mathrm{I}_{8}$ and ${ }^{5} \mathrm{I}_{7}$, which is $5117 \mathrm{~cm}^{-1}$ in $\mathrm{Cs}_{2} \mathrm{NaHoCl}_{6}$. The high-energy group is not well-resolved to enable detailed assignments to be made and in $\mathrm{Cs}_{2} \mathrm{NaH}-$ $\mathrm{oCl}_{6}$ the structure is mainly vibronic in nature. Comparison of the lower energy group, ${ }^{5} \mathrm{~S}_{2} \rightarrow{ }^{5} \mathrm{I}_{7}$, with the corresponding spectrum in $\mathrm{Cs}_{2} \mathrm{NaHoCl}_{6}$ shows that the two stronger bands correspond to the $v_{6}\left(135 \mathrm{~cm}^{-1}\right)$ and $v_{4}\left(166 \mathrm{~cm}^{-1}\right)$ vibronic origins. The weak band at $695 \mathrm{~nm}\left(14380 \mathrm{~cm}^{-1}\right)$ between the two groups does not correspond to emission from ${ }^{5} \mathrm{~F}_{5}$, but is alternatively assigned to

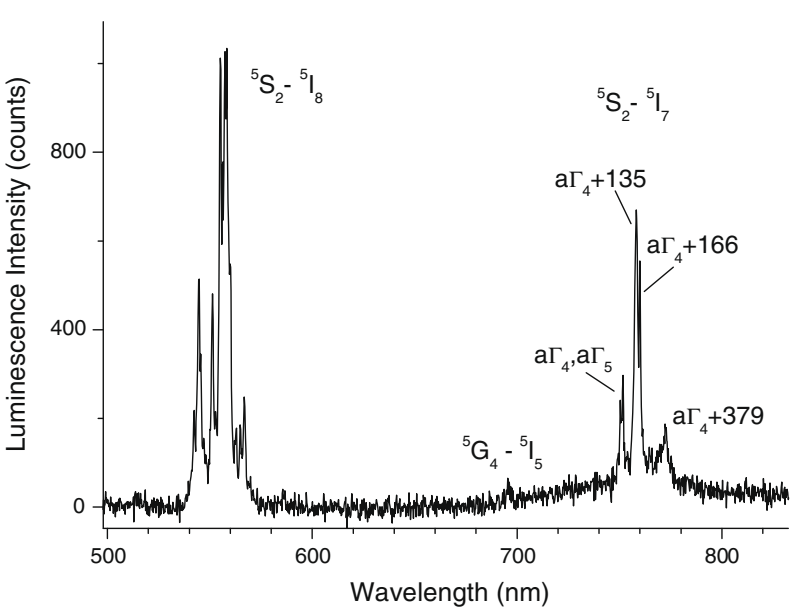

Fig. 4. $12.3 \mathrm{~K}$ emission spectrum of $\mathrm{Cs}_{2} \mathrm{NaYF}_{6}: \mathrm{Ho}^{3+}(10 \%)$ excited by $119.2 \mathrm{~nm}$ synchrotron radiation, between $500 \mathrm{~nm}$ and $820 \mathrm{~nm}$. The terminal levels of the ${ }^{5} \mathrm{~S}_{2} \rightarrow{ }^{5} \mathrm{I}_{7}$ transition are marked. 
the ${ }^{5} \mathrm{G}_{4} \rightarrow{ }^{5} \mathrm{I}_{5}$ transition, reported also for $\mathrm{Cs}_{2} \mathrm{NaHoCl}_{6}$ [34], inferring that ${ }^{5} \mathrm{G}_{4}$ is located at $\sim 25,900 \mathrm{~cm}^{-1}$.

\section{5. $\mathrm{Er}^{3+}$}

The VUV-excited luminescence of $\mathrm{Cs}_{2} \mathrm{NaYF}_{6}: \mathrm{Er}^{3+}$ has previously been reported [13]. In addition to the interconfigurational $4 \mathrm{f}^{10} 5 \mathrm{~d} \rightarrow 4 \mathrm{f}^{11}$ emission, $4 \mathrm{f}^{11} \rightarrow 4 \mathrm{f}^{11}$ luminescence was observed from the ${ }^{2} \mathrm{~F}(2)_{7 / 2}$ multiplet term. The intraconfigurational luminescence from lower multiplet terms of $\mathrm{Er}^{3+}$ in $\mathrm{Cs}_{2} \mathrm{NaErF}_{6}$ has recently been reported, and the emission from $\mathrm{Cs}_{2} \mathrm{NaMF}_{6}: \mathrm{Er}^{3+}(\mathrm{M}=\mathrm{Ga}, \mathrm{Sc})$ was also recorded but not reported [7]. From the observed splitting of spectral features at $10 \mathrm{~K}$ in the $487 \mathrm{~nm}$ excited emission spectra in the $\mathrm{Cs}_{2} \mathrm{NaGaF}_{6}$ host lattice, as compared with analogous single bands in the spectra of $\mathrm{Cs}_{2} \mathrm{NaErF}_{6}$, it was concluded [7] that $\mathrm{Er}^{3+}$ is located at two different sites in $\mathrm{Cs}_{2} \mathrm{NaGaF}_{6}$. However, since the relevant spectral features involve emission from $\Gamma_{8}$ states, an alternative explanation for the splitting is that the 4 -fold symmetry axis of $\mathrm{ErF}_{6}{ }^{3-}$ is no longer present. The two-site explanation is consistent with crystallographic data, where two crystallographically inequivalent sites I and II were found for trivalent Ga. The band splittings are not resolved in the $77 \mathrm{~K}$ emission spectra of $\mathrm{Cs}_{2} \mathrm{NaGa}-$
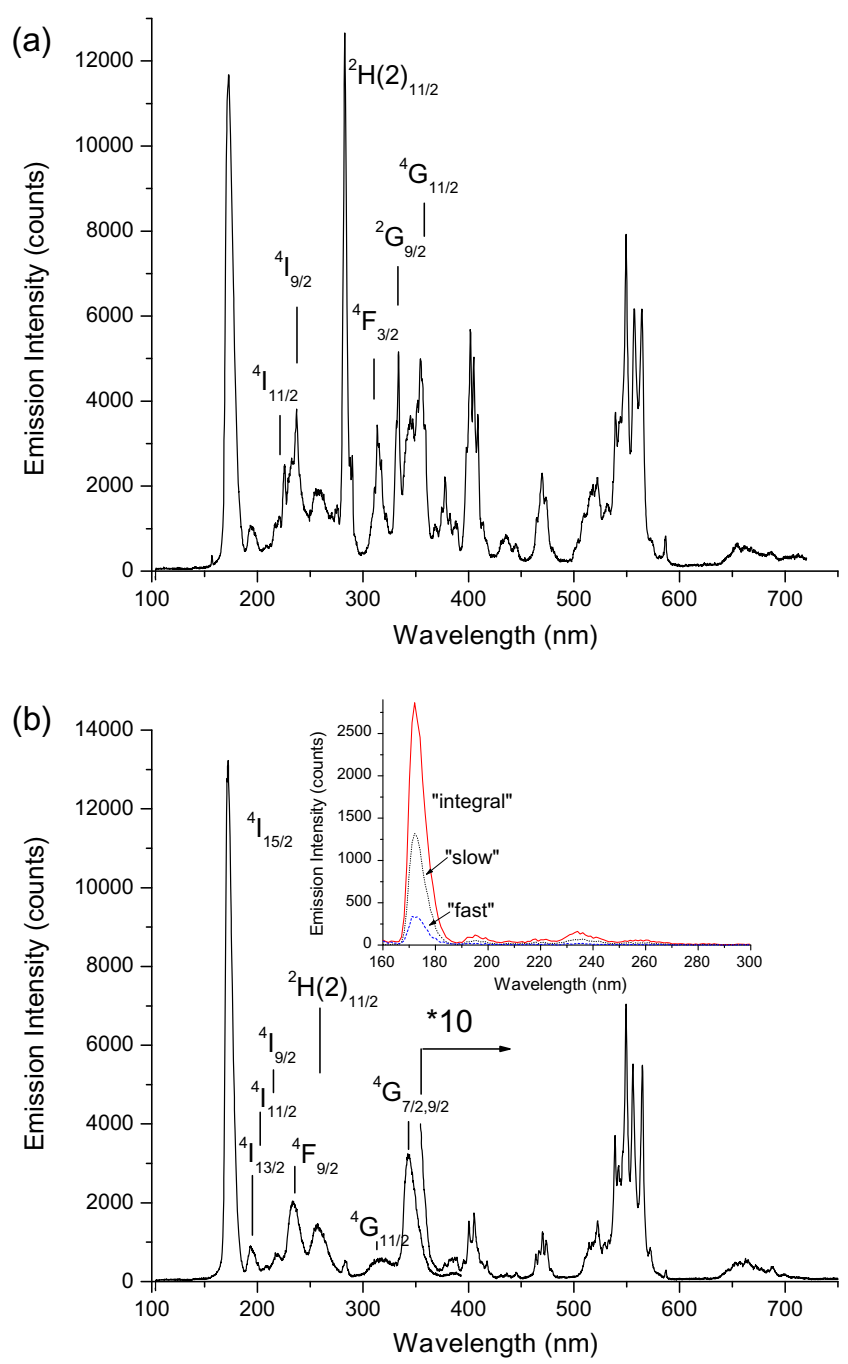

Fig. 5. $157 \mathrm{~nm}$ excited emission spectra of $\mathrm{Cs}_{2} \mathrm{NaMF}_{6}: \mathrm{Er}^{3+}(50 \%)$ at $300 \mathrm{~K}$ between $100 \mathrm{~nm}$ and $720 \mathrm{~nm}$ : (a) $\mathrm{M}=\mathrm{Ga}$. (b) $\mathrm{M}=\mathrm{Sc}$. The inset in (b) shows the time-resolved emission between $160 \mathrm{~nm}$ and $300 \mathrm{~nm}$ using synchrotron radiation excitation. Refer to the text for explanation.
$\mathrm{F}_{6}: \mathrm{Er}^{3+}$ and since $487 \mathrm{~nm}$ excited emission spectra are generally similar to that of $\mathrm{Cs}_{2} \mathrm{NaYF}_{6}: \mathrm{Er}^{3+}$ the sites are similar, and in fact only differ by the linkage of the $\mathrm{GaF}_{6}$ moiety to $\mathrm{NaF}_{6}$ octahedra.

Fig. $5 a$ and $b$ shows the emission spectra of $\mathrm{Cs}_{2} \mathrm{NaMF}_{6}: \mathrm{Er}^{3+} \mathrm{ex}-$ cited by a $\mathrm{F}_{2}$ laser. There are some interesting differences between these spectra, and also with that of $\mathrm{Cs}_{2} \mathrm{NaYF}_{6}: \mathrm{Er}^{3+}$. The inset of Fig. 5b shows that the highest energy emission of $\mathrm{Cs}_{2} \mathrm{NaScF}_{6}: \mathrm{Er}^{3+}$ is relatively slow (i.e. the decay time is longer than the experimental limit of the setup, which is restricted by the repetition period $480 \mathrm{~ns}$ of synchrotron radiation pulses). The calculated onset of the $4 \mathrm{f}^{10} 5 \mathrm{~d}$ absorption commences at $58,400 \mathrm{~cm}^{-1}(171 \mathrm{~nm})$ and since the state mainly comprises high spin ${ }^{6}\left[\left({ }^{5} \mathrm{I}\right) \mathrm{t}_{2 \mathrm{~g}}\right]$ parentage, the $5 \mathrm{~d}-4 \mathrm{f}$ emission transition is spin-forbidden to the $4 \mathrm{f}^{11}$ ground state ${ }^{4} I_{15 / 2}$. The $\mathrm{J}$ value for the lowest state is mainly $17 / 2$ so that from the $\Delta J$ selection rule for electric dipole emission, most of the intensity is expected to reside in the transition to ${ }^{4} I_{15 / 2}$. The terminal $4 \mathrm{f}^{11}$ multiplet terms of the $5 \mathrm{~d}-4 \mathrm{f}$ emission are marked in Fig. 5b and the maximum of the first, most intense band, to ${ }^{4} \mathrm{I}_{15 / 2}$ is at $172.2 \pm 0.1 \mathrm{~nm}\left(58,070 \pm 50 \mathrm{~cm}^{-1}\right)$. Spin-allowed $5 \mathrm{~d}-4 \mathrm{f}$ emission is not observed.

Fig. 5a differs from Fig. 5b in that the intraconfigurational emission is relatively stronger and is superimposed upon broader interconfigurational bands. This is noticeable from the peak at $282.7 \mathrm{~nm}$ $\left(35370 \mathrm{~cm}^{-1}\right)$ which is strong in (a), but weak in (b). The reason why the nonradiative relaxation from $5 \mathrm{~d}$ to $4 \mathrm{f}$ levels is faster in (a) is not due to the concentration of $\mathrm{Er}^{3+}$, but is related to the lower $\left(D_{3 d}\right)$ site symmetry of $\mathrm{Er}^{3+}$, although the centre of symmetry is retained. The $4 \mathrm{f}^{11}$ luminescent state is ${ }^{2} \mathrm{~F}(2)_{7 / 2}$, which is estimated to be at $54,500 \pm 200 \mathrm{~cm}^{-1}$ from the terminal level locations in Fig. 5a and their tabulation in [7]. Note that luminescence from this multiplet term was not observed in $\mathrm{Cs}_{2} \mathrm{NaErCl}_{6}$ under synchrotron radiation excitation because it lies above the band gap in the chloride host lattice [35]. The strongest intraconfigurational transition in Fig. $5 \mathrm{a}$ is the $\Delta J=2$ transition to ${ }^{2} \mathrm{H}(2)_{11 / 2}$. Transitions from ${ }^{2} \mathrm{~F}(2)_{7 / 2}$ to some other multiplet terms are marked in the figure. The bands are not sufficiently well-resolved at wavelengths longer than $350 \mathrm{~nm}$ to provide unambiguous assignments. In the case of $\mathrm{Cs}_{2} \mathrm{NaYF}_{6}: \mathrm{Er}^{3+}$ [13], emission was indicated from ${ }^{2} \mathrm{P}_{3 / 2}$. This multiplet is located at $31367 \mathrm{~cm}^{-1}$ in $\mathrm{Cs}_{2} \mathrm{NaErCl}_{6}$ [7]. Other possible luminescent multiplet terms are ${ }^{2} \mathrm{I}_{11 / 2},{ }^{2} \mathrm{H}(2)_{9 / 2},{ }^{4} \mathrm{D}_{5 / 2},{ }^{4} \mathrm{G}_{11 / 2}$, and ${ }^{2} \mathrm{G}_{9 / 2}$, as well as ${ }^{4} \mathrm{~S}_{3 / 2}$ at lower energy, and higher resolution spectra are required for secure assignments.

\section{Conclusions}

Except for the occurrence of sharp magnetic dipole transitions in the emission spectrum of $\mathrm{Sm}^{3+}$, the assignment of the intraconfigurational $4 \mathrm{f}^{\mathrm{N}} \rightarrow 4 \mathrm{f}^{\mathrm{N}}$ emission spectra of $\mathrm{Cs}_{2} \mathrm{NaYF}_{6}: \mathrm{Ln}^{3+}$ herein is confined to assignments of multiplet-multiplet transitions. Since the highest phonon energy in these systems corresponds to the Ln-F symmetric stretching mode $\left(460-480 \mathrm{~cm}^{-1}\right)$ and an energy gap of 4-5 phonons is required below a luminescent state, then the separation must be $>2000 \mathrm{~cm}^{-1}$. For $\mathrm{Sm}^{3+}$, this is only the case for a lower energy level with visible emission, whereas for $\mathrm{Ho}^{3+}$, the emission from ${ }^{5} \mathrm{G}_{4}$ (in the ultraviolet spectral region) is extremely weak. For $\mathrm{Er}^{3+}$ doped in $\mathrm{LiYF}_{4}(2 \%)$, under $182.9 \mathrm{~nm}$ excitation, $4 \mathrm{f}^{11} \rightarrow 4 \mathrm{f}^{11}$ emission was demonstrated from ${ }^{2} \mathrm{~F}(2)_{7 / 2}$ $\left(\sim 54,700 \mathrm{~cm}^{-1}\right)$ as in the present case, with additional very weak emission assigned to originate from ${ }^{2} \mathrm{P}_{3 / 2}\left(\sim 31,600 \mathrm{~cm}^{-1}\right)[36,37]$, which is concentration-quenched. These results agree with those reported for $\mathrm{Cs}_{2} \mathrm{NaYF}_{6}: \mathrm{Er}^{3+}$ [13]. In addition, for $\mathrm{LiYF}_{4}: \mathrm{Er}^{3+}(2 \%)$ it was stated that under excitation at $207.9 \mathrm{~nm}$ or $195.6 \mathrm{~nm}$, emission from ${ }^{4} \mathrm{D}_{1 / 2}\left(\sim 47,200 \mathrm{~cm}^{-1}\right)$ was observed [36].

Upon excitation by synchrotron radiation, $5 d-4 f$ emission has been observed for $\mathrm{Er}^{3+}$, but not for $\mathrm{Sm}^{3+}, \mathrm{Gd}^{3+}, \mathrm{Tb}^{3+}$, and $\mathrm{Ho}^{3+}$. 
The complex $4 \mathrm{f}^{\mathrm{N}}$ energy level schemes of $\mathrm{Sm}^{3+}, \mathrm{Tb}^{3+}$, and $\mathrm{Ho}^{3+}$ permit facile nonradiative decay from $4 \mathrm{f}^{\mathrm{N}-1} 5 \mathrm{~d}$ levels. The failure to observe $5 \mathrm{~d}-4 \mathrm{f}$ emission from $\mathrm{Gd}^{3+}$ in the elpasolite host was surprising since $4 f^{6} 5 d \rightarrow 4 f^{7}$ emission has been observed in several other fluoride host lattices $[30,31,38]$.

\section{Acknowledgements}

Financial support for this work under the Hong Kong Research Grants Council GRF research grant CityU 102308 is gratefully acknowledged. C.K.D. is partially supported by the National Science Foundation of China, under Grant No. 10874253. This work was also supported by the RFBR Grant 06-02-39027-NNSF, by the Estonian Science Foundation (Grant No. 6538); and by European Community Research Infrastructure Action within the FP6 Program (Contract RII3-CT-2004-506008 (IA-SFS)).

\section{References}

[1] P.A. Tanner, Top. Curr. Chem. 241 (2004) 167.

[2] P.A. Tanner, C.-K. Duan, V.N. Makhov, M. Kirm, N.M. Khaidukov, submitted for publication.

[3] P.A. Tanner, L. Ning, V.N. Makhov, N.M. Khaidukov, M. Kirm, J. Phys. Chem. B 110 (2006) 12113.

[4] P.A. Tanner, Y.-L. Liu, N. Edelstein, K. Murdoch, N.M. Khaidukov, J. Phys.: Condens. Matter 9 (1997) 7817.

[5] A.J. Berry, D.Phil. Thesis, University of Oxford, 1995.

[6] A.J. Berry, I.D. Morrison, R.G. Denning, Mol. Phys. 93 (1998) 1.

[7] X.-J. Zhou, P.A. Tanner, M.D. Faucher, J. Phys. Chem. C 111 (2007) 683.

[8] P.A. Tanner, M.D. Faucher, Chem. Phys. Lett. 445 (2007) 183.

[9] M.L. Falin, K.I. Gerasimov, A.M. Leushin, N.M. Khaidukov, J. Lumin. 128 (2008) 1103.

[10] B.F. Aull, H.P. Jenssen, Phys. Rev. B 34 (1986) 6640.

[11] B.F. Aull, H.P. Jenssen, Phys. Rev. B 34 (1986) 6647
[12] D. Schiffbauer, C. Wickleder, G. Meyer, M. Kirm, M. Stephan, P.C. Schmidt, Z. Anorg. Allg. Chem. 631 (2005) 3046.

[13] V.N. Makhov, N.M. Khaidukov, D. Lo, J.C. Krupa, M. Kirm, E. Negodin, Opt. Mater. 27 (2005) 1131.

[14] C. Ma, P.A. Tanner, S. Xia, M. Yin, Opt. Mater. 29 (2007) 1620.

[15] G. Meyer, Prog. Solid State Chem. 14 (1982) 141.

[16] J.-L. Huang, X.-Y. Kuang, Y. Li, Chem. Phys. Lett. 458 (2008) 227.

[17] R.J.M. da Fonseca, A.D. Tavares Jr., P.S. Silva, T. Abritta, N.M. Khaidukov, Solid State Commun. 110 (1999) 519.

[18] R.D. Shannon, Acta Cryst. A 32 (1976) $751 . \quad<$ http://abulafia.mt.ic.ac.uk/ shannon/>.

[19] G. Zimmerer, Radiat. Meas. 42 (2007) 859.

[20] L. van Pieterson, M.F. Reid, R.T. Wegh, S. Soverna, A. Meijerink, Phys. Rev. B 65 (2002) 045113

[21] D.R. Foster, F.S. Richardson, R.W. Schwartz, J. Chem. Phys. 82 (1985) 618.

[22] P.A. Tanner, Chem. Phys. Lett. 155 (1989) 59.

[23] J.-P.R. Wells, M. Yamaga, T.P.J. Han, H.G. Gallagher, M. Honda, Phys. Rev. B 60 (1999) 3849.

[24] J.B. Gruber, B. Zandi, M. Ferry, L.D. Merkle, J. Appl. Phys. 86 (1999) 4377.

[25] M.D. Faucher, P.A. Tanner, J. Phys.: Condens. Matter 18 (2006) 8503.

[26] A.J. de Vries, G. Blasse, J. Chem. Phys. 88 (1988) 7312

[27] G.H. Dieke, L. Leopold, J. Opt. Soc. Am. 47 (1957) 944.

[28] W.T. Carnall, P.R. Fields, R. Sarup, J. Chem. Phys. 54 (1971) 1476.

[29] P.J. Deren, W. Strek, J.-C. Krupa, Chem. Phys. Lett. 298 (1998) 217.

[30] M. Kirm, J.C. Krupa, V.N. Makhov, M. True, S. Vielhauer, G. Zimmerer, Phys. Rev. B 70 (2004) 241101.

[31] M. Kirm, G. Stryganyuk, S. Vielhauer, G. Zimmerer, V.N. Makhov, B.Z. Malkin, O.V. Solovyev, R. Yu Abdulsabirov, S.L. Korableva, Phys. Rev. B 75 (2007) 075111.

[32] H.-D. Amberger, Z. Anorg. Allg. Chem. 467 (1980) 231.

[33] P.A. Tanner, J. Chem. Soc. Faraday Trans. 283 (1987) 1367.

[34] X. Zhou, P.A. Tanner, Chem. Phys. Lett. 413 (2005) 284.

[35] X. Zhou, P.A. Tanner, C.K. Duan, B.-M. Cheng, Chem. Phys. Lett. 442 (2007) 302.

[36] R.T. Wegh, E.V.D. Van Loef, G.W. Burdick, A. Meijerink, Mol. Phys. 101 (2003) 1047.

[37] N.M. Khaidukov, N.Yu. Kirikova, M. Kirm, J.C. Krupa, V.N. Makhov, E. Negodin G. Zimmerer, Proc. SPIE 4766 (2002) 154.

[38] V.N. Makhov, S.Kh. Batygov, L.N. Dmitruk, M. Kirm, G. Stryganyuk, G. Zimmerer, Phys. Status Solidi (c) 4 (2007) 881. 